Проанализировав пути продвижения гостиничныхуслуг на казахстанском рынке, мы определили такие основные, как реклама в средствах массовой информации, прямой маркетинг, стимулирование продаж и связи с общественностью. Каждый из них является достаточно эффективным и дает свои результаты в течение определенного периода времени. Однако современное общество развивается очень быстрыми темпами, особенно информационное пространство, что в свою очередь стимулирует производителей гостиничных продуктов искать все новые пути для их продвижения на рынке. Проанализировав существующую ситуацию, можно рекомендовать более активное использование современных информационных технологий для рекламы услуг гостиничного предприятия.

$$
* * *
$$

1. Кабушкин Н.И. Организация туризма: учебное пособие/ Н.И. Кабушкин, А.П. Дурович, Г.А. Бондаренко, Т.М. Сергеева - 3-е изд., испр. - М.: Новое знание, 2006. - 640 с.

2. Котлер Ф. Маркетинг. Гостеприимство и туризм: Учебник / Котлер Ф., Боуэн Д., Мейкенз Д., 2007.

3. Лесник А.Л., Чернышев А.В. Практика маркетинга в гостиничном и ресторанном бизнесе. - М.: ЮНИТИ, 2008. - 234 с.

4. Синяева И.М. Маркетинговые коммуникации / И.М. Синяева, С.В. Земляк, В.В. Синяев - М.: Издательско-торговая корпорация «Дашков и К», 2015. - 304 с.

5. Бутко, И. И. Маркетинг в туризме / И.И. Бутко, В.А. Ситников, Е.А. Ситников. - Москва: РГГУ, 2013. - $412 \mathrm{c}$.

6. Симонян Т. В. Маркетинг и маркетинговые коммуникации / Т.В. Симонян, Т.Г. Кизилова. - М.: Феникс, 2011. - 224 с.

7. Дурович А. П. Маркетинг в туризме. Учебное пособие / А.П. Дурович, А.С. Копанев. - М.: Экономпресс, 2013. - 400 c.

\title{
Лавриненко Е.A. \\ Рекомендации по улучшению качества принятия инвестиционных решений по вновь инициируемымпроектам
}

Белгородский государственный национальный исследовательский университет (Россия, Белгород)

doi:10.18411/spc-14-01-2018-08

idsp: 000001:spc-14-01-2018-08

Каждый руководитель предприятия осуществляющий реальное инвестирование в целях своего развитиядолжен стараться улучшать свою инвестиционную позицию путем объективной оценки эффективности инвестиционных проектов и своевременного реинвестирования капитала при наступлении неблагоприятных обстоятельств для осуществления отдельных проектов в их прединвестиционной и постинвестиционных стадиях.В связи с этим в систему оперативного управления инвестиционной программы предприятия должны входить меры не только по успешной реализации, но и улучшения качества принятия инвестиционных решения по вновь инициируемым проектам.

Вновь инициируемые проекты - это те проекты, которые ранее по той или иной причине были отложены и находились в инвестиционном портфеле предприятия в ожидание момента благоприятной рыночной конъюнктуры.

1. Основополагающей рекомендацией при оценке вновь инициируемого инвестиционного проекта является внедрение системы упреждающего мониторинга инвестиционных проектов основанной на взаимосвязанных процессах и обратной связи [2].

С целью нивелирования будущих негативных последствий упреждающий мониторинг вновь инициируемых инвестиционных проектов (ИП) должен осуществляться на следующих стадиях прединвестиционного этапа (рис.1). 


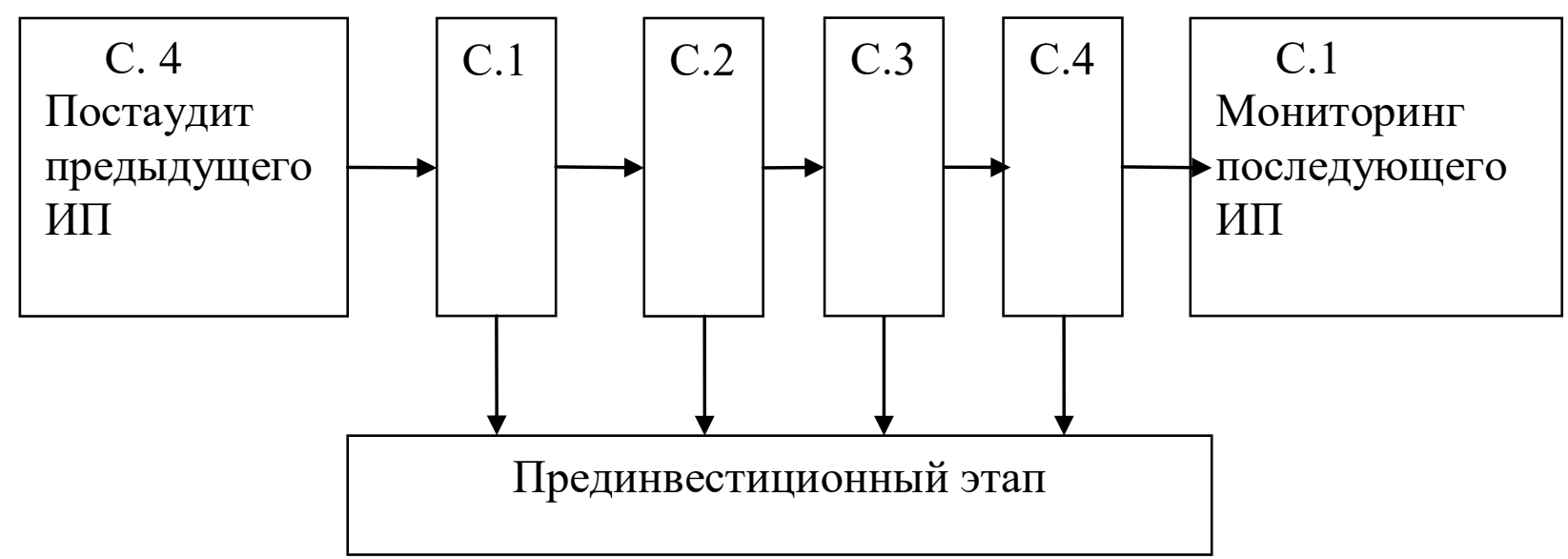

Рисунок 1. Модель постадийного разделения прединвестиционного этапа инвестиционного проекта

2. В системе упреждающего мониторинга инвестиционных проектов до принятия решения об инвестирование в прединвестиционную стадию рекомендуется включить:

- оценку инвестиционных возможностей всех аналогичных отложенных проектов;

- постаудит аналогичных предыдущих инвестиционных проектов;

- предварительное технико - экономическое обоснование инвестиционных проектов;

- анализ и выбор наиболее эффективного вновь инициируемого проекта.

Следует отметить, что время, затраченное на расширение стадий припроведение упреждающем мониторинге прединвестиционной этапа проекта и постаудита предыдущего инвестиционного проекта многократно окупится; подобные затраты являются своего рода инвестициями, так как позволяют в дальнейшем сэкономить значительные средства, в том числе в случае отказа от «нежизнеспособного» проекта.

3. Система упреждающий мониторинга вновь инициируемых инвестиционных проектов на прединвестиционном этапе должна быть основанная на непрерывной оценке и обратной связи, что позволит обеспечить переход к качественно новому уровню эффективности и результативности функционирования экономических систем. Под обратной связью понимается непрерывность процесса мониторинга, эксперт в каждом последующем проекте должен опираться на полученную информацию и знания в предыдущем проекте. Поэтому для получения полной и достоверной информации после завершения проекта, проводят постаудит. На данной стадии подводятся итоги реализации инвестиционного проекта, основанные на критериях эффективности использования инвестированных средств, достижения поставленных целей, возможности снижения риска, максимизации прибыли и пр.

4. Чтобы оценить, возможна ли инициация проекта, надо тщательно проанализировать все сильные и слабые стороны, например, провести SWOT-анализ. Это может быть:

- обстановка в стране, где будет реализоваться проект;

- особенность его месторасположения;

- отношения компаний, имеющих к нему причастность;

- особенности местного рынка и способов реализации продукции;

- специфика финансирования;

- организация безопасности;

- способы снижения рисков; 
- возможность использования местных ресурсов.

Модифицированный SWOT-анализ входящий в систему упреждающего мониторинга инвестиционных проектоввключает в себя взамен традиционных (сильные, слабые стороны проекта; риски и возможности), выгоды, издержки, возможности и риски (табл.1.).

Таблийа 1

МодифицииованныйSWOT-анализ инвестициионных проектов

\begin{tabular}{|c|c|}
\hline +позитив & -негатив \\
\hline выгоды & издержки \\
\hline возможности & риски \\
\hline
\end{tabular}

Таким образом, под оценкой возможности инициации проекта на прединвестиционном этапе в рамках системы упреждающего мониторинга будем понимать такую оценку, которая учитывает полный набор последствий, имеющий место на этом шаге:

- поступления денежных средств за вычетом текущих расходов, или притоки денежных средств (выгоды);

- инвестиционные затраты, или оттоки денежных средств (издержки);

- управленческие возможности (возможности);

- риск денежного потока (риски).

5. Сравнение прогнозных и фактических показателей на выходе, при проведение упреждающего мониторинга новь инициируемых инвестиционных проектов предполагает:

- осуществление количественного и качественного анализа тенденций инвестиционных процессов, существующих проблем и новых явлений;

- альтернативное предвидение будущего изменения рыночной конъюнктуры для расширения возможных объектов вложения капитала;

- оценку возможностей и последствий вложения средств в техническое перевооружение предприятия [3].

Данная рекомендация необходима как для корректного подведения итогов реализации инвестиционного проекта, так и для передачи знаний при реализации следующего инвестиционного проекта.

Следовательно, для улучшения качества принятия инвестиционных решений по вновь инициируемым проектам необходимо соблюдать принципы многоэтапности и обратной связи, которые требуют построения структуры выгод, издержек, возможностей и рисков для формирования приоритетных направлений инвестиционной политики предприятия. Сложность, многоаспектность, наличие большого числа обратных связей обусловливают необходимость использования разнообразных подходов и методов при выборе вновь инициируемого инвестиционного проекта, что в свою очередь соответствует применению системы упреждающего мониторинга инвестиционных проектов на предприятии.

$$
* * *
$$

1. Исследование выполнено при финансовой поддержке РФФИ в рамках научного проекта № 16 - 36 00408мол_а

2. Лавриненко Е.А. Модели и методы системы упреждающего мониторинга на начальном этапе жизненного цикла инвестиционного проекта/ Новая наука: современное состояние и пути развития. Издательство: Общество с ограниченной ответственностью "Агентство международных исследований" (Уфа) //2016. С.95-99

3. Синергетика инвестиций: учеб.-метод. пособие / О.С.Сухарев, СВ. Шманёв, А.М. Курьянов; под ред. профессора О.С. Сухарева. М.: Финансы и статистика; ИНФРА-М, 2008. 368 с: 